\section{Rotator cuff disease - basics of diagnosis and treatment}

\author{
Robert E. Boykin,' Hinrich J.D. Heuer,' \\ Suketu Vaishnav, ${ }^{2}$ Peter J. Millett ${ }^{2}$ \\ 'Department of Orthopedic Surgery, \\ Massachusetts General Hospital, Boston, \\ MA, USA \\ 2Steadman-Philippon Research Institute, \\ Vail, CO, USA
}

\section{Abstract}

Rotator cuff (RTC) disease is a particularly prevalent cause of shoulder pain and weakness presenting to primary care physicians, internists, rheumatologists, and orthopedists. An understanding of the anatomy of the RTC tendons and the underlying pathogenesis aids in the diagnosis, which is based largely on history and specific physical examination tests. Imaging may further define the pathology and aid in the evaluation of other sources of shoulder pain. Injuries to the RTC range from tendonitis to partial thickness tears to full thickness tears. The majority of patients with impingement and some cases of partial thickness tears may be managed effectively with non-operative measures including nonsteroidal anti-inflammatory drugs, local injections, and physical therapy. Predictors of a good outcome with non-operative treatment include pre-injury strength, ability to raise the arm to the level of the shoulder, and a more acute presentation. Persistent symptoms may require operative intervention including debridement, subacromial decompression, and/or RTC repair. Acute full thickness tears in younger patients in addition to failed nonoperative management of full thickness tears in older patients are the most likely to require surgery, which may be done open or arthroscopically. The majority of tears are amenable to the less invasive arthroscopic method, which yields good success rates and high patient satisfaction.

\section{Introduction}

Shoulder pathology remains a common etiology of pain and disability presenting to primary care physicians, internists, rheumatologists, and orthopedic surgeons. Secondary to the complex nature of the shoulder joint, the differential diagnosis of shoulder pain is broad and may entail a number of causes from infection, osteoarthritis, rheumatologic disease, fracture, neuropathy, or soft tissue injury including that to the labrum and musculotendinous units supporting the joint. Rotator cuff disease in particular is a common cause of shoulder pain and weakness and comprises a significant proportion of the musculoskeletal complaints presenting to primary care doctors. ${ }^{1}$ Injury to the tendons of the RTC may be seen in a wide spectrum of ages, from the younger athlete with an acute injury to the older patient with degeneration of the cuff. ${ }^{1,2}$ These injuries may be full thickness or partial thickness tears of one or more of the RTC tendons ${ }^{3}$ and although some can be managed non-operatively, others may potentially benefit from surgical management. ${ }^{4}$ This review will highlight the diagnosis and management of RTC disease.

\section{Epidemiology}

Overall, shoulder pain accounts for approximately three million visits to physicians each year in the United States, and of these RTC disease is the most common cause of shoulder pain necessitating a visit to a primary care physician. ${ }^{5}$ It is estimated that $21-27 \%$ of all elderly patients suffer from some form of shoulder pain. ${ }^{1}$ As early as 1934 , Codman noted a $32 \%$ prevalence of supraspinatus rupture in the general population. ${ }^{6}$ More recent data from cadaveric studies demonstrated a $7 \%$ prevalence of full thickness and 13\% partial thickness RTC tears, ${ }^{3}$ while the incidence is known to increase with older age. ${ }^{7}$ Imaging studies have also been performed, including a magnetic resonance imaging (MRI) study of 96 asymptomatic patients aged 19-39 years revealing no full thickness tears and a $4 \%$ prevalence of partial thickness RTC tears. ${ }^{8}$ In patients over the age of 60 years, there was a $28 \%$ prevalence of full thickness and $26 \%$ partial thickness tears. ${ }^{8}$ Another ultrasound study revealed a $5-11 \%$ incidence of RTC tears in asymptomatic patients aged 40-60 years, but up to $80 \%$ prevalence in patients over the age of 80 years. ${ }^{9}$ A recent study of 1366 patients in Japan by Yamamoto et al. demonstrated a $20.7 \%$ prevalence of RTC tears with risk factors including age, dominant arm, and a history of trauma. ${ }^{10}$ RTC pathology is asymptomatic in a number of patients; however, there are a reasonable number of people at risk for developing debilitating pain.

\section{Anatomy}

The RTC consists of four muscles and the interdigitation of their tendinous insertions onto the humerus (Figure 1).

The supraspinatus, infraspinatus, sub-
Correspondence: Peter J. Millett, Steadman Philippon Research Institute, 181 West Meadow Drive, Suite 1000, Vail, C0 81657, USA.

E-mail: drmillett@steadmanclinic.net

Key words: rotator cuff tear, shoulder impingement syndrome, tendinopathy, rotator cuff repair, shoulder.

Contributions: all authors contributed equally and substantively to the research, writing, and editing of the manuscript.

Acknowledgments: we would like to thank Grant E. Norte ATC and Bradley C. Register MD for the demonstration of a subacromial injection, and Martin J. Bee for his illustrations as well as Ryan P. Kunkel for his help with finalizing the manuscript.

Conflict of interest: $\mathrm{RB}, \mathrm{HH}$, and SV report no conflicts of interest; PM is a consultant for Arthrex Inc., Naples, Florida, and Game Ready Inc., Alameda, California, USA. Research support was received from Smith and Nephew Inc. Memphis, Tennessee, USA.

Received for publication: 20 November 2009.

Revision received: 10 February 2010.

Accepted for publication: 11 February 2010.

This work is licensed under a Creative Commons Attribution 3.0 License (by-nc 3.0).

(C) Copyright R.E. Boykin et al., 2010

Licensee PAGEPress, Italy

Rheumatology Reports 2010; 2:e1

doi:10.4081/rr.2010.e1

scapularis, and teres minor muscles all originate from the scapula and insert on the proximal humerus. The supraspinatus and infraspinatus muscles are supplied by the suprascapular nerve $(\mathbf{C} 5,6)$ of the upper trunk of the brachial plexus and insert on the greater tuberosity of the humerus. The main function of the supraspinatus is abduction, while that of the infraspinatus is external rotation of the arm. The teres minor muscle is supplied by the axillary nerve (C5), inserts on the greater tuberosity of the humerus, and also provides external rotation of the arm. The subscapularis muscle is supplied by the upper and lower subscapular nerves (C5-7) and provides internal rotation through its attachment to the lesser tuberosity of the humerus.

The RTC muscles provide both motion of the glenohumeral joint and serve as dynamic stabilizers to maintain the normal relationship of the glenoid and the humeral head. The shoulder has an extremely large range of motion (ROM) with a subsequent risk of instability secondary to a shallow glenoid and a large humeral head. In the absence of the RTC and loss of dynamic stabilization, the deltoid will elevate the humeral head rather than abduct 
the arm. The shoulder joint is also maintained by a number of static stabilizers including the labrum, ligamentous restraints, intra-articular negative pressure, and capsular thickenings (inferior, middle, and superior glenohumeral ligaments).

The bony structure of the shoulder connects the appendicular skeleton to the axial skeleton. The scapula serves as the origin or attachment of 17 muscles, and the glenoid portion articulates with the humerus to form the true shoulder joint. The coracoid process extends medially and serves as the attachment for a number of muscles and ligaments. The acromion process of the scapula overhangs the humeral head and certain anatomic variants and activities may predispose patients to impingement of the RTC under the acromion. ${ }^{11,12}$

\section{Pathogenesis}

The pathogenesis of RTC tears has long been debated and revolves around both intrinsic and extrinsic factors. Initial descriptions by Codman proposed that damage to the RTC was intrinsic from degenerative changes. ${ }^{6}$ Later Neer proposed an extrinsic mechanism through impingement of the RTC against the acromion in the subacromial space. ${ }^{13}$ More recently, both internal impingement and secondary impingement have been described. ${ }^{14}$ The exact mechanism of injury is still not clearly defined, and it appears that there are likely both intrinsic and extrinsic factors that contribute to injury. ${ }^{4}$ RTC injury may occur on the bursal side or articular side of the tendon. It appears that degenerative tendinopathy of the supraspinatus muscle is typically articularsided and found in older patients whereas bursal-sided tears may be more commonly seen in younger, overhead athletes. Additional work has suggested that articular-sided tears of the infraspinatus muscle may also be seen through a mechanism of internal impingement in overhead athletes. ${ }^{14}$

It is likely that a combination of these processes, including impingement in a degenerative tendon, leads to tearing and chronic symptoms of pain. Intrinsic degeneration of the RTC tendons is thought to be secondary to both repetitive microtrauma and hypoperfusion of a critical area of the tendon. ${ }^{15}$ The process of impingement is hypothesized to lead to partial and then to full thickness tears of the RTC, typically in a tendon with pre-existing degeneration. The most common form of impingement is external, caused by compression of the supraspinatus tendon under the coracoacromial arch secondary to a narrowed humeroacromial space. ${ }^{16}$ The process leads to inflammation of the subacromial bursa with

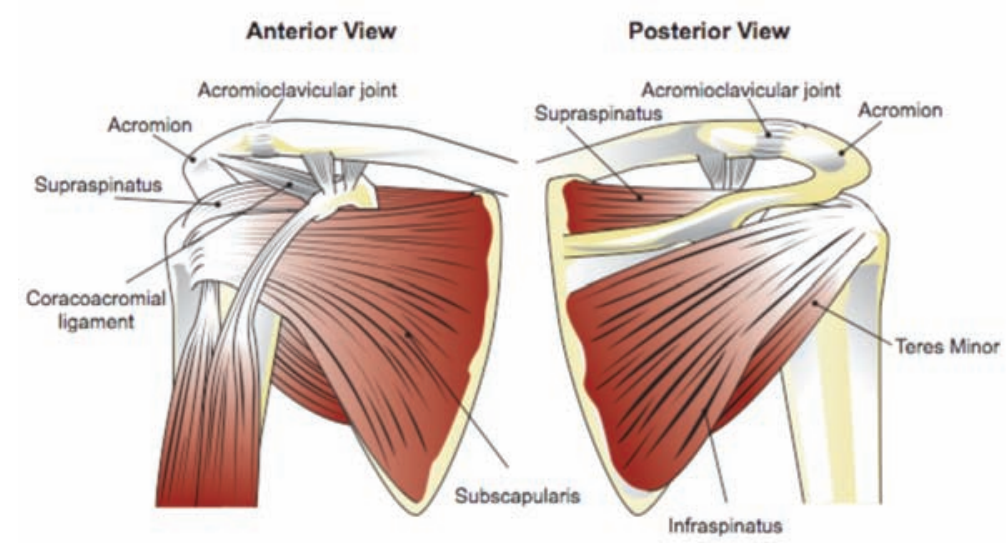

Figure 1. Anatomy of the RTC tendons - right shoulder.

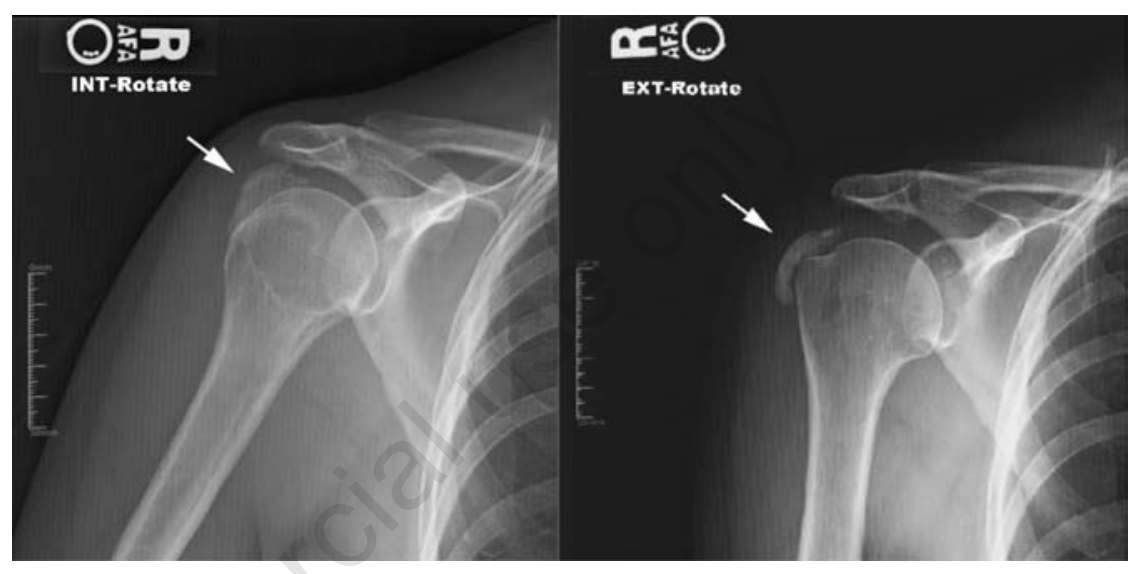

Figure 2. Anterior-posterior radiographs of the shoulder in internal and external rotation demonstrating calcific tendonitis of the supraspinatus tendon (arrow).

resultant pain, dysfunction of the RTC with superior migration, and a further decrease in space available for the RTC. Inflammatory mediators are released, further contributing to the pain from impingement. Studies have demonstrated increased levels of IL-1B and IL1 receptor antagonists in addition to substance $P$ in the subacromial bursa of patients with a RTC tear. ${ }^{17,18}$ Internal impingement is caused by repetitive motion of the infraspinatus tendon over the posterosuperior aspect of the glenoid, ${ }^{14}$ while secondary impingement (non-outlet impingement) may be caused by glenohumeral instability or by adhesive capsulitis, both of which alter glenohumeral kinematics and can produce symptoms of impingement.

\section{Classification}

RTC tears are typically classified as full thickness tears or partial thickness tears, depending on the extent of the tendon involved. The supraspinatus is the most commonly involved tendon. ${ }^{6}$ Partial thickness tears are further stratified by both location and size.
The majority of these tears occur on the articular side of the supraspinatus ${ }^{20}$ although there may also be bursal-sided tears and interstitial tears. In addition, partial thickness RTC tears can be graded by the depth of tearing, as grade I: $<3 \mathrm{~mm}$, grade II: $3-6 \mathrm{~mm}$, and grade III: $>6 \mathrm{~mm}$ deep (Table 1). When less than $50 \%$ of the thickness of the tendon is involved and there is no retraction, surgical repair is often unnecessary and debridement alone may suffice. ${ }^{19}$ While most partial thickness tears involve the supraspinatus tendon, in younger patients involved in overhead sports, tears may occur at the supraspinatus/infraspinatus interval owing to the repetitive motion causing internal impingement. ${ }^{14}$ Calcific tendonitis, although not a true tear but more of a dissection of the tendon by calcium hydroxyapatite deposition, may present with symptoms such as pain that mimic a tear and thus may be confused with a partial tear. It often causes severe pain and can be differentiated by the presence of calcifications within the RTC tendons on radiographs (Figure 2).

A full thickness RTC tear refers to one that involves a complete separation of the tendon from the proximal humeral attachment site 

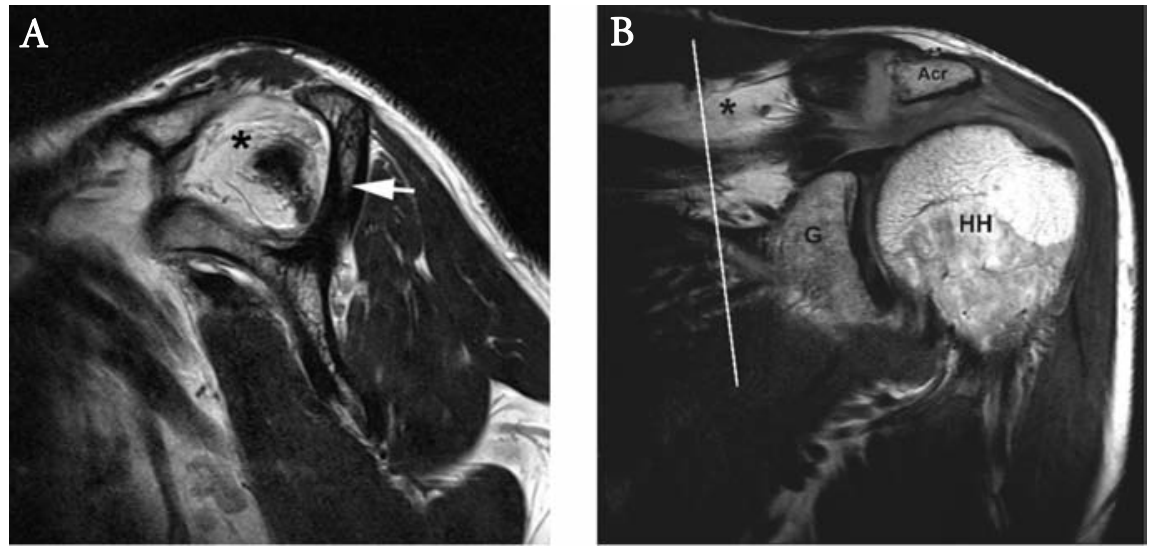

Figure 3. Magnetic resonance image demonstrating fatty degeneration of the supraspinatus muscle: A, T2 spin echo, sagittal plane, showing fatty degeneration of the supraspinatus tendon $\left({ }^{*}\right)$ and scapula (arrow). B, T2 spin echo showing fatty degeneration in coronal plane; white line demonstrating the plane of the sagittal image, glenoid $(G)$, humeral head $(\mathrm{HH})$, and acromion (Acr).

with resultant communication between the glenohumeral joint and the subacromial space. They are classified as acute or chronic and also by size. The size classification is based on the largest dimension of the tear with $<1 \mathrm{~cm}=$ small, $1-3 \mathrm{~cm}=$ medium, $3-5 \mathrm{~cm}=$ large, and $>5 \mathrm{~cm}=$ massive, or by the number of tendons involved (one, two, or three tendon tears) (Table 2). ${ }^{19,20}$ Tears that are longstanding or chronic in nature may result in atrophy and fatty degeneration of the muscle (Table 3 , Figure 3$).^{22}$

\section{Presentation}

The patient with a tear of the RTC may present to their primary care physician, rheumatologist, or orthopedist with a wide range of complaints, although the history typically involves pain in the shoulder with overhead activities and pain at night. The patient may report stiffness in the shoulder or weakness in abduction, forward flexion, and/or external rotation of the arm. Any history of trauma is important to elicit, and it is essential to differentiate patients with impingement type symptoms (pain with overhead activities) from those with symptoms of a full RTC tear (weakness, inability to raise the arm).$^{20,25}$ Age should be a consideration along with baseline and desired activity levels. An acute traumatic event in a younger patient or an acute-on-chronic event in an older patient with a sudden increase in pain or weakness may signify a full thickness tear, whereas a more insidious onset with progressive pain and no or mild weakness is more likely to represent a partial thickness tear. Full thickness tears can also be atraumatic and degenerative in nature. In these cases, if left untreated, there can be subsequent atrophy and fatty infiltration of the RTC musculature over time. Patients with a full thickness injury may report more weakness in forward flexion and abduction of the arm and difficulties with activities of daily living requiring these motions. Partial thickness tears may cause stiffness and pain owing to the increased tension on the remaining RTC fibers. ${ }^{26}$ Studies have shown that partial tears with subacromial bursitis may have more pain and increased nocturnal pain. ${ }^{3,27}$

\section{Physical examination}

The examination of a patient with shoulder pain should consist of a full examination of the cervical spine to exclude referred pain from cervical spondylosis, radiculopathy, or stenosis. This should include ROM in neck flexion, extension, lateral bending, and rotation, palpation for any tenderness, Sperling's maneuver (a dynamic test for cervical radiculopathy), and a thorough neurologic examination. This should be followed by a visual inspection of both shoulders to assess for asymmetry and loss of muscle bulk, scapular winging, or atrophy. In particular, the supraspinatus and infraspinatus muscles should be assessed for asymmetry. The sternoclavicular (SC) joint, clavicle, acromioclavicular (AC) joint, greater tuberosity of the humerus, anterior shoulder, and posterior shoulder should then be palpated for tenderness or abnormality. AC joint pathology and biceps tendonitis (manifested as pain on palpation of the anterior shoulder) are common causes of shoulder pain that frequently occur in the same setting as RTC disease.

Next, shoulder ROM and strength should be noted. Always start the examination with the non-painful shoulder to gain a baseline for strength and ROM. The examination should include both active and passive ROM in for-
Table 1. Classification of partial thickness RTC tears.

A. Classification of RIC tears (Ellman). ${ }^{19}$
Location of partial-thickness tears
\begin{tabular}{ll} 
A & Articular surface \\
B & Bursal surface \\
\hline C & Interstitial \\
B. Classification of RIC tears (Ellman). ${ }^{19}$ \\
Grading of partial-thickness tears \\
Grade & Depth \\
I & $<3 \mathrm{~mm}$ \\
\hline II & $3-6 \mathrm{~mm}$ \\
III & $>6 \mathrm{~mm}$
\end{tabular}

Table 2. Classifications of full thickness RTC tears.

\begin{tabular}{|c|c|}
\hline \multicolumn{2}{|c|}{$\begin{array}{l}\text { A. Classification of RTC tears (Ellman). }{ }^{19} \\
\text { Location of full-thickness tearstear }\end{array}$} \\
\hline A & Supraspinatus \\
\hline & Infraspinatus \\
\hline & Teres minor \\
\hline & Subscapularis \\
\hline
\end{tabular}

B. Classification of RTC tears (Ellman). ${ }^{19}$ Grading of full-thickness tears

\begin{tabular}{ll} 
Grade & Largest dimension of tear \\
I small & $<2 \mathrm{~cm}$ \\
\hline II medium & $2-4 \mathrm{~cm}$ \\
III large & $>5 \mathrm{~cm}$ \\
\hline IV & Cuff arthropathy
\end{tabular}

C. Classification of RTC tears (Cofield et al. $)^{21}$ Grading of full-thickness tears

\begin{tabular}{ll} 
Grade & Largest dimension of tear \\
I small & $<1 \mathrm{~cm}$ \\
\hline II medium & $1-3 \mathrm{~cm}$ \\
III large & $3-5 \mathrm{~cm}$ \\
\hline IV massive & $>5 \mathrm{~cm}$
\end{tabular}

Table 3. Goutallier (A) and Fuchs (B) classification of fatty degeneration of the RTC muscles.

\begin{tabular}{|c|c|}
\hline \multicolumn{2}{|c|}{$\begin{array}{l}\text { A. Classification for fatty degeneration } \\
\text { of RTC muscles on CT scan. Grading } \\
(\text { Goutallier et al. })^{23}\end{array}$} \\
\hline Grade 0 & No fatty streaks \\
\hline Grade 1 & Some fatty streaks \\
\hline Grade 2 & More muscle than fat \\
\hline Grade 3 & As much muscle as fat \\
\hline Grade 4 & Less muscle than fat \\
\hline
\end{tabular}

No or some fatty streaks Normal muscle

More muscle than fat Moderate degeneration

As much muscle as fat Advanced degeneration or less muscle than fat 
ward flexion (FF) and abduction (ABD), in addition to external (ER) and internal rotation (IR) at 0 and 90 degrees of abduction. Passive ROM in most cuff tears is typically preserved but may elicit pain. Active ROM may be decreased to varying degrees in full or partial thickness tears depending on which tendon is injured.

Strength and functional testing should include FF, ABD, ER, IR, and elbow flexion/forearm supination against resistance by the examiner. The deltoid muscle serves as the principal abductor while the biceps serves to supinate the forearm and flex the elbow. Deltoid detachment or rupture is rare and usually post-surgical in cause, but it is easily identified on examination. The rotator cuff can be divided into three functional groups for strength testing: internal rotation (subscapularis), external rotation (infraspinatus and teres minor), and forward flexion (supraspinatus). Specific functional tests include the empty can test, full can test, and drop arm test for the supraspinatus, the hornblower's sign to evaluate the infraspinatus and teres minor, and the belly press and lift off test to evaluate the subscapularis (Figure 4). ${ }^{28,29}$

If it is difficult to tell whether a patient has true weakness or decreased function secondary to pain, a diagnostic subacromial injection of local anesthetic (impingement test) may eliminate pain and allow for improved functional testing (Figure 5). Provocative testing is also used for impingement, shoulder instability, AC joint pathology, and biceps tendonitis. Specific impingement signs as described by Neer $^{16}$ and Hawkins and Kennedy ${ }^{30}$ include passive forward flexion of the arm, abduction of the arm to 90 degrees, and internal rotation, respectively. These tests have been shown to be sensitive but lack specificity, as have most tests reported for impingement. ${ }^{31,32}$ Shoulder instability is tested by the apprehension and relocation tests. Pain originating at the $\mathrm{AC}$ joint is elicited by the crossed arm adduction test by bringing the forward flexed arm across the body. Inflammation of the biceps tendon is tested by direct palpation and by Speed's and Yergason's tests, including resisted flexion of the elbow and resisted supination of the forearm with the elbow at 90 degrees, respectively (Table 4).

\section{Differential diagnosis}

The differential diagnosis for shoulder pain is based on the history, acute or chronic nature of the pain, and physical examination. For a patient presenting with acute pain and a discrete event, one should consider a fracture of the clavicle or proximal humerus, an AC joint dislocation or sprain, or a shoulder dislocation
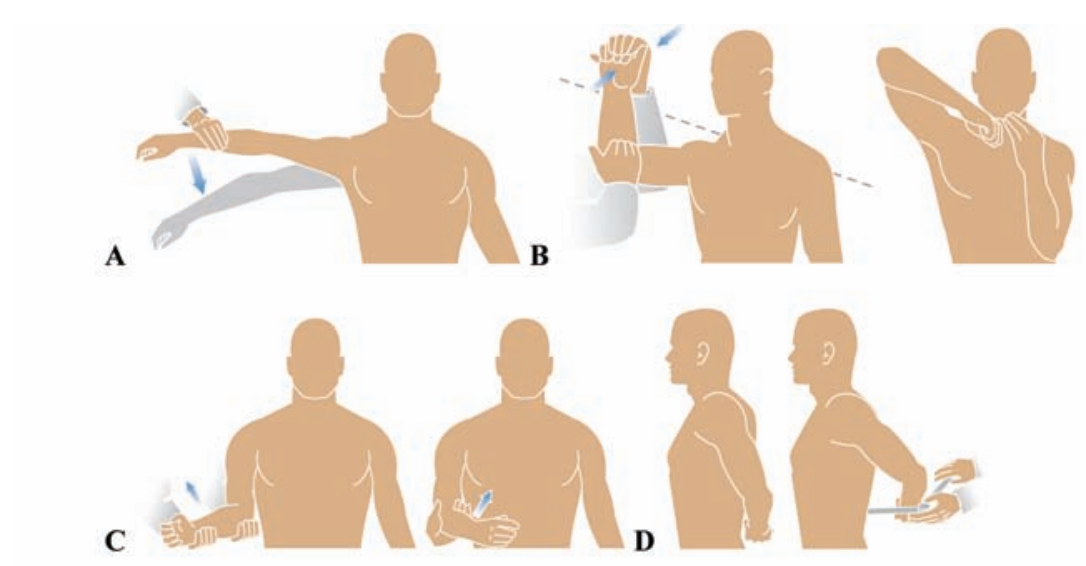

Figure 4. Lag tests in diagnosis of RTC tears. A, drop arm sign, pathologic for supraspinatus insufficiency if the patient cannot hold the passively elevated arm in place or if the arm cannot be lowered slowly without dropping. B, hornblower's sign, pathologic for teres minor insufficiency if external rotation weakness or lag occurs at $90^{\circ}$ abduction in the scapular plane or if the patient's elbow rises above hand level, when the hand is raised to the mouth. C, external rotation lag, pathologic for infraspinatus insufficiency if the passively external rotated arm cannot be held in position as shown. D, lift off test, pathologic for subscapularis insufficiency if the passively maximally internally rotated arm cannot be held elevated from the back. If elevation is possible, hand-back distance can be measured and compared to the other side.

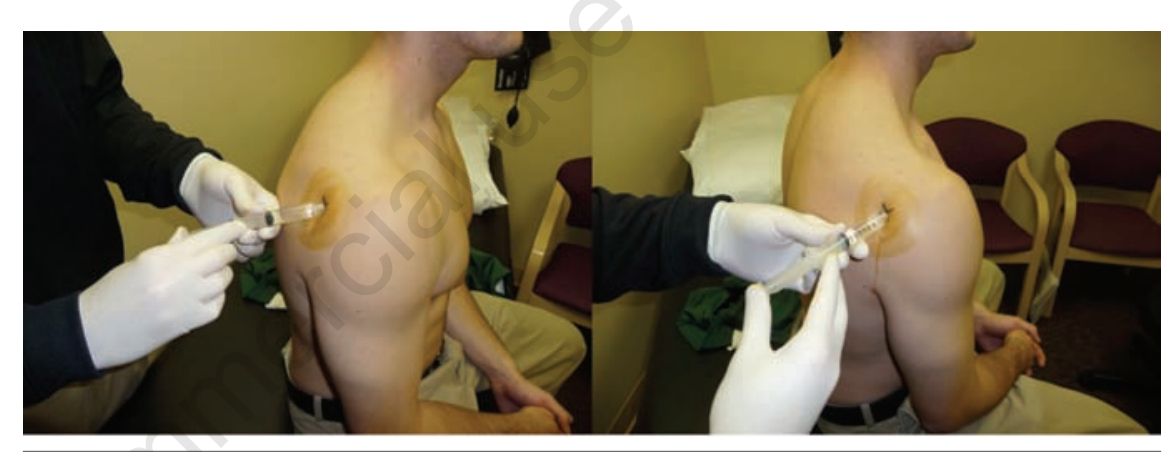

Figure 5. Demonstration of a subacromial injection. The injection is made $1 \mathrm{~cm}$ inferior and $1 \mathrm{~cm}$ medial from the posterolateral tip of the acromion. To inject into the subacromial space, the syringe should be aimed at the anterior tip of the acromion.

in addition to a RTC tear. For more chronic complaints, the differential diagnosis includes calcific tendonitis, biceps tendonitis, adhesive capsulitis, or osteoarthritis. These can occur in conjunction with a RTC tear. Less common chronic etiologies include infection (septic arthritis or bursitis), rheumatoid arthritis, gout, or a tumor of the shoulder. Shoulder pain may also be referred from other areas such as the cervical spine or viscera including the heart, lungs, diaphragm, or spleen. In the appropriate clinical settings, these areas should be carefully evaluated as well. ${ }^{33}$

\section{Imaging}

The initial radiographic evaluation of shoulder pain should begin with plain radiographs, including an anterior-posterior view (AP), axillary view, and an outlet view. The AP may show degenerative changes, calcific tendonitis, or superior migration of the humeral head. Narrowing of the acromio-humeral interval (superior migration) is frequently seen in large RTC tears, with at least two tendons torn (Figures 6 and 7) ${ }^{34}$

In advanced RTC disease, secondary arthropathy (RTC arthropathy) may occur with arthritic changes such as glenohumeral joint space narrowing, subchondral sclerosis, osteophytes, and subchondral cysts noted..$^{35}$

An axillary view rules out a shoulder dislocation and may also demonstrate degenerative changes with loss of joint space, consistent with osteoarthritis. The outlet view can show acromial spurring, which causes narrowing of the subacromial space and has been correlated with full thickness RTC tears (Figure 8).$^{35}$

In cases where the etiology of pain is unclear from the plain films or when a RTC is suspected on physical examination, further imaging may be pursued. Arthrography and bursography were previously used to supplement plain radiographs, but have largely been 
Table 4. Physical examination of the shoulder.

\begin{tabular}{|c|c|c|}
\hline Structures to be tested & $\begin{array}{l}\text { al examination of the shoulder } \\
\text { Test }\end{array}$ & $\begin{array}{l}\text { Conclusions of the tests } \\
\text { differential diagnosis }\end{array}$ \\
\hline Cervical spine & $\begin{array}{l}\text { Range of motion (ROM) } \\
\text { flexion } \\
\text { extension } \\
\text { lateral bending } \\
\text { rotation } \\
\text { Palpation for tenderness } \\
\text { Sperling's maneuver } \\
\text { (dynamic test for cervical } \\
\text { radiculopathy) } \\
\text { Full neurologic examination }\end{array}$ & $\begin{array}{l}\text { Cervical spondylosis } \\
\text { Cervical stenosis } \\
\text { Cervical radiculopathy }\end{array}$ \\
\hline Shoulder & $\begin{array}{l}\text { Visual inspection } \\
\text { of both shoulders }\end{array}$ & $\begin{array}{l}\text { Asymmetry (supraspinatus } \\
\text { and infraspinatus) } \\
\text { Loss of muscle bulk } \\
\text { Scapular winging } \\
\text { Atrophy }\end{array}$ \\
\hline $\begin{array}{l}\text { Neighboring structures } \\
\text { Sternoclavicular (SC) joint } \\
\text { Clavicle } \\
\text { Acromioclavicular (AC) joint } \\
\text { Greater tuberosity } \\
\text { Anterior shoulder } \\
\text { Posterior shoulder }\end{array}$ & Palpation & $\begin{array}{l}\text { Tenderness } \\
\text { Abnormalities } \\
\text { AC-joint pathology } \\
\text { Biceps tendonitis }\end{array}$ \\
\hline $\begin{array}{l}\text { Shoulder always examine non- } \\
\text { painful side first }\end{array}$ & $\begin{array}{l}\text { Active \& passive ROM } \\
\text { Strength testing } \\
\text { forward flexion (FF) } \\
\text { abduction (ABD) } \\
\text { at } 90^{\circ} \text { elbow flexion } \\
\text { external rotation (ER) } \\
\text { internal rotation (IR) } \\
\text { at } 0^{\circ} \text { and } 90^{\circ} \mathrm{ABD} \\
\text { forearm supination } \\
\text { against resistance } \\
\text { Special functional testing } \\
\text { empty can test } \\
\text { full can test } \\
\text { drop arm test } \\
\text { external rotation lag sign } \\
\text { hornblower's sign } \\
\text { belly press test } \\
\text { lift off test } \\
\text { Impingement tests by } \\
\text { Neer } \\
\text { Hawkins and Kennedy } \\
\text { Shoulder instability } \\
\text { apprehension test } \\
\text { relocation test } \\
\text { AC-pathology } \\
\text { cross-arm adduction test } \\
\text { Biceps tendonitis } \\
\text { palpation of anterior shoulder } \\
\text { Speed's test } \\
\text { Yergason's test }\end{array}$ & $\begin{array}{l}\text { Weakness/loss of function } \\
\rightarrow \text { RTC tear } \\
\text { supraspinatus } \\
\text { infraspinatus or teres minor } \\
\text { subscapularis } \\
\text { biceps tendonitis } \\
\text { supraspinatus } \\
\text { infraspinatus } \\
\text { teres minor } \\
\text { subscapularis } \\
\text { subacromial impingement }\end{array}$ \\
\hline
\end{tabular}

replaced by ultrasound (US), MRI, and MRarthrography secondary to disparate unsatisfying data on accuracy. ${ }^{36-38}$ In addition, radiation to the patient is reduced by the use of US or MR techniques. Computerized tomography (CT) and CT-arthrography are most helpful in evaluating bony defects of the shoulder and can be used to assess the RTC. However, they are not the best current test for the visualization of soft tissues, and they expose patients to the highest amount of radiation. Charousset $e t$ al. indicated that CT arthrogaphy had a sensitivity of $64-99 \%$ and a specificity of $98-100 \%$ for detection of tears of the different rotator cuff tendons..$^{39}$ CT-based imaging is non-optimal for imaging of soft tissues including the RTC tendons, but may provide an alternative in patients with a contraindication to an MRI. In addition, US imaging may be used to evaluate the rotator cuff (Figure 9).

US has a distinct advantage secondary to the fact that it allows for dynamic testing, allowing the arm to be moved actively or passively during the examination. In addition, it is inexpensive and readily available at most centers. The major disadvantage of the technique

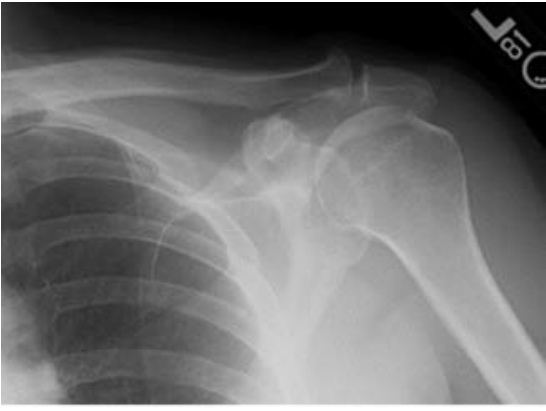

Figure 6. Anterior-posterior radiograph of the shoulder demonstrating superior migration of the humeral head in a RTC tear.

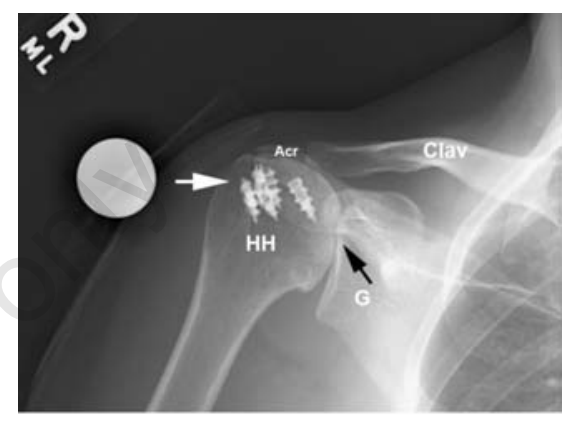

Figure 7. Anterior-posterior radiograph of the shoulder demonstrating RTC arthropathy after failed repair: the humeral head (HH) superiorly migrated and the joint space highly decreased (black arrow), remaining metal suture anchors from a failed repair (white arrow), as well as the clavicle (Clav), glenoid (G), and acromion (Acr) can be identified.

is that it is highly dependent on the skills of the examiner as stressed by Hedtmann and Fett ${ }^{40}$ and by Ziegler. ${ }^{41}$ Hedtmann and Fett state that better results regarding sensitivity and specificity are seen in studies with larger numbers of examined patients. ${ }^{40}$ US is also unable to evaluate other sources of shoulder pain including labral tears, biceps tendon pathology, and other intra-articular issues.

MRI and MRI-related techniques have become standard for evaluation of the rotator cuff in many centers (Figure 10).

Plain MRI, although expensive, provides a detailed view of the RTC tendons in addition to other concomitant shoulder pathology including labral tears, biceps tendon pathology, and any other intra-articular sources of shoulder pain. ${ }^{42,43}$ It can be useful in preoperative planning as it provides a three-dimensional view of the shoulder and associated injuries. The drawbacks of the technique include high cost and the possibility of false positive results.

In comparison, US and MRI have been shown to have a similar sensitivity, specificity, and overall accuracy. ${ }^{446} \mathrm{~A}$ study by Ziegler ${ }^{41}$ on US showed a specificity of $94.1 \%$ and sensitivity of $96.1 \%$ for partial or full thickness RTC 
tears, while a paper by Teefey et al. revealed an overall accuracy of $87 \%{ }^{45}$ Fotiadou et al. showed an accuracy of $98 \%$ for full thickness tears and $87 \%$ for partial thickness tears utilizing US. ${ }^{46}$ MRI has been shown to have near $100 \%$ sensitivity and 95\% specificity in full thickness RTC. ${ }^{47}$ MR-arthrography provides the benefits of MRI with an enhanced visualization of the RTC and intra-articular structures. A meta-analysis showed that MR-arthrography was significantly superior to plain MRI and US in regard to sensitivity and specificity of full and partial thickness tears. ${ }^{44}$ Stetson et al. ${ }^{48}$ showed a sensitivity of $91 \%$ and a specificity of $85 \%$ for detecting articular-sided partial thickness tears, while Waldt et al. ${ }^{49}$ showed an accuracy of $95 \%$ for partial and $98 \%$ for full thickness tears. Sensitivity and specificity were $80 \%$ and $97 \%$ for partial and $96 \%$ and $99 \%$ for full thickness tears. However, it remains questionable whether this advantage will still be present if MR-arthrography were to be compared with MRI on the newer 3-Tesla scanners.

\section{Treatment}

The goal of treatment of rotator cuff pathology is to restore functional capacity, treat pain, and prevent long-term sequelae including arthrosis. This may include non-operative treatment (medical and physical therapy) or surgical intervention. The decision for type of treatment depends on the patient's age, preinjury functional status, comorbidities, and type of RTC tear. Factors that delay healing include the use of nicotine, diabetes mellitus, and chronic corticosteroid use..$^{50}$ For example, partial thickness tears and impingement are typically treated with rest, activity modification, and non-steroidal anti-inflammatory drugs (NSAIDs), followed by a course of physical therapy. Larger tears may also be treated non-operatively depending on their chronicity; however, debilitating acute tears may fare better from early operative management. Otherwise, surgery in RTC is usually reserved for those who have failed a course of conservative management.

\section{Non-operative management and results}

Non-operative treatment of RTC consists of a combination of anti-inflammatory medications, local corticosteroid injections, and physical therapy. Medical treatment may be divided into systemic and local modalities. Systemic treatment includes acetaminophen in doses of $<4000 \mathrm{mg}$ /day for pain relief, or NSAIDs prescribed on a standing basis to reduce inflammation and pain at the RTC and subacromial bursa. The Cox-2 inhibitors may be an alterna-
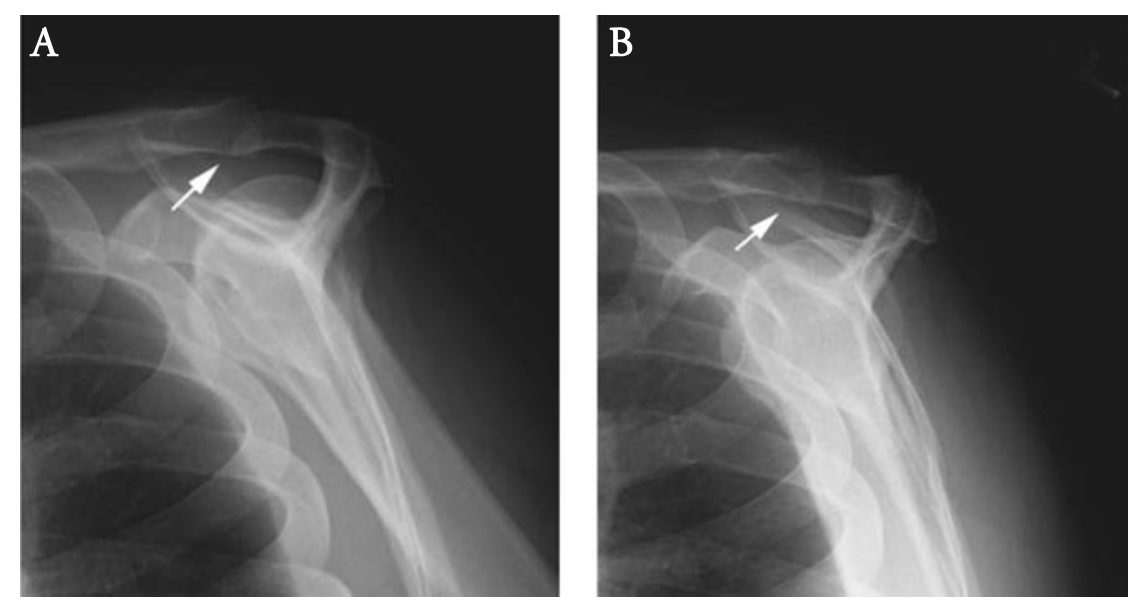

Figure 8. Outlet view radiographs of the shoulder demonstrating a subacromial bone spur/type III acromion (arrow) before (A) and after (B) an arthroscopic subacromial decompression.
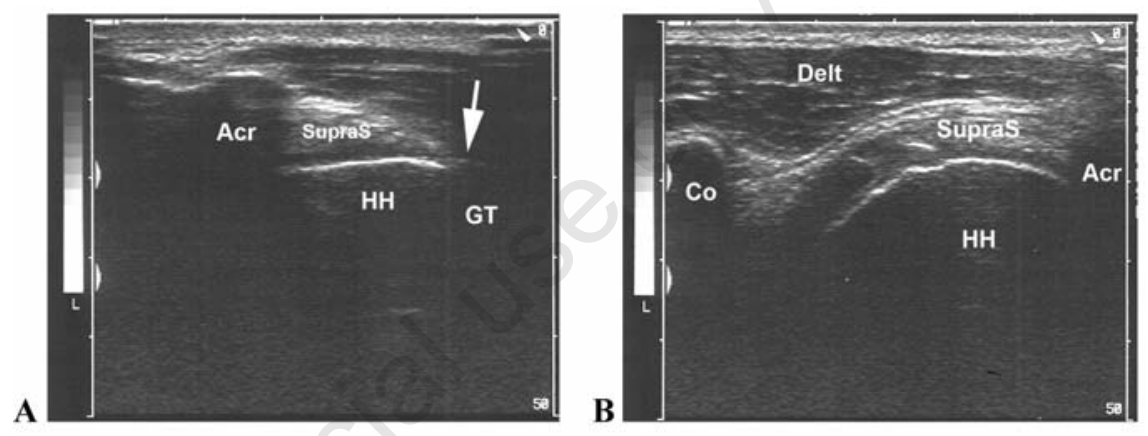

Figure 9. A, 7.5 MHz US image of the insertion of a normal supraspinatus tendon (arrow) attaching to the greater tuberosity (GT) of the humerus - long-axis or longitudinal view; $\mathrm{B}, 7.5 \mathrm{MHz}$ US image showing the profile of the supraspinatus (SupraS) - short-axis or transverse view. Surrounding structures: humeral head (HH), acromion (Acr), coracoid process $(\mathrm{Co})$, deltoid muscle (Delt).

tive to prevent the gastrointestinal side effects of traditional NSAIDs; however, there remains a question of cardiovascular risk. One metaanalysis showed a relative risk of myocardial infarction of 1.9 (95\% confidence interval 1.3 to 2.6) in patients treated with COX-2 inhibitors, compared with placebo.$^{51}$ The AHA consensus statement is that COX-2 inhibitors be analgesics of last resort in patients with

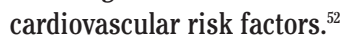

Local modalities include injections of corticosteroid and local anesthetic into the subacromial bursa. This is typically reserved for patients with continued pain after therapy and may be given every 3-6 months for a total of three injections. A study has shown that injections given too frequently or directly into the tendon may precipitate tendon rupture. ${ }^{53}$

Physical therapy consists of a progression of exercises directed first at pain control, then initiating ROM, finally strengthening. ROM will prevent stiffness of the shoulder and subsequent strengthening will restore function and stabilize the shoulder. Therapists may also utilize other modalities such as US or laser

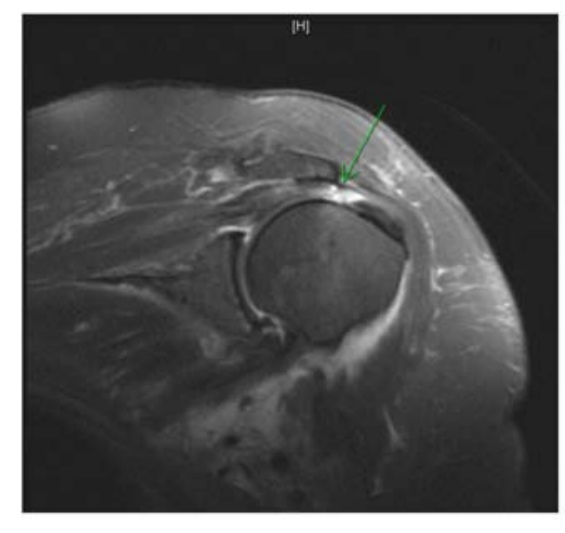

Figure 10. T2 magnetic resonance image, coronal plane, demonstrating a tear of the supraspinatus tendon (arrow).

therapy for pain control, although these are not of scientifically proven benefit.

The results of non-operative treatment and natural history of RTC tears continues to be debated. A study by Bokor et al. showed 74\% pain relief with non-operative treatment of 
Table 5. Comparison of further specific imaging techniques.

\begin{tabular}{|c|c|c|c|}
\hline Technique & Pro & Contra & Cost estimate \\
\hline US & $\begin{array}{l}\text { Good visualization of RTC tendons } \\
\text { Dynamic testing possible } \\
\text { Low costs } \\
\text { Availability }\end{array}$ & $\begin{array}{l}\text { Unable to evaluate deep structures of shoulder } \\
\text { (e.g. labrum) } \\
\text { Highly dependent on examiner skills }\end{array}$ & $\begin{array}{l}\text { Bilateral examination } / \$ 450-\$ 500 \\
\text { (US-Unit } / \$ 9,000-\$ 20,000) \\
\left(\text { Ziegler }^{41}\right)\end{array}$ \\
\hline MRI & $\begin{array}{l}\text { Good visualization of RTC tendons } \\
\text { Good visualization of concomitant } \\
\text { injuries such as labrial tears } \\
\text { Good operative planning possible }\end{array}$ & $\begin{array}{l}\text { High costs } \\
\text { Possible false positive results } \\
\text { Availability }\end{array}$ & $\begin{array}{l}\text { Unilateral examination } / \$ 1,200-\$ 2,600 \\
\text { (Highly dependent on facility price) }\end{array}$ \\
\hline MR-arthrography & $\begin{array}{l}\text { Superior to conventional MRI and US in } \\
\text { respect of sensitivity and specificity of } \\
\text { detection of RTC tears } \\
\text { Also see MRI }\end{array}$ & $\begin{array}{l}\text { High costs } \\
\text { Invasiveness } \\
\text { Availability }\end{array}$ & $\begin{array}{l}\text { Unilateral examination / } \$ 4,000-\$ 4,500 \\
\text { (Highly dependent on facility price) }\end{array}$ \\
\hline CT & Good evaluation of bony defects & $\begin{array}{l}\text { High exposure to radiation } \\
\text { No good visualization of soft tissue such as RTC } \\
\text { Availability } \\
\text { High Costs }\end{array}$ & $\begin{array}{l}\text { Unilateral examination } / \$ 1,500-\$ 1,700 \\
\text { (Highly dependent on facility price) }\end{array}$ \\
\hline CT-arthrography & $\begin{array}{l}\text { Good evaluation of bones combined } \\
\text { with reasonable evaluation of RTC }\end{array}$ & $\begin{array}{l}\text { High exposure to radiation } \\
\text { Invasiveness } \\
\text { Availability } \\
\text { High Costs }\end{array}$ & $\begin{array}{l}\text { Unilateral examination / } \$ 2,500-\$ 2,800 \\
\text { (Highly dependent on facility price) }\end{array}$ \\
\hline
\end{tabular}

Costs have been estimated from the current rates at a facility in the United States.

arthroscopically proven full thickness RTC tears. ${ }^{54}$ Predictors of a good outcome with nonoperative treatment include pre-injury strength, ability to raise the arm to the level of the shoulder, and a more acute presentation..$^{54,55}$ Negative predictive factors include an outstanding insurance claim..$^{56}$ Another study has shown that the natural history of tears is one of progression, with symptomatic tears becoming larger and asymptomatic tears becoming symptomatic.

Studies regarding the use of traditional NSAIDs have shown few differences among the various varieties, with the major side effect being gastrointestinal complaints. ${ }^{57-61}$ In regard to the Cox-2 inhibitors, a study has noted a similar efficacy of Celecoxib to Naproxen for shoulder pain. ${ }^{62}$ In doses of $200 \mathrm{mg}$, Celecoxib has not been shown to have an increased cardiovascular risk, but overall the class of Cox-2 inhibitors has been proven to lead to increased atherothrombosis..$^{51,52,63}$ The efficacy of local injections of corticosteroids is highly dependent on the accuracy of the injection. Previous reports have illustrated an accur-acy of 29-70\% with outcomes being much better with an accurate injection. ${ }^{6466}$ To improve the reliability of injections, US guidance may be of some benefit. ${ }^{67}$ A meta-analysis illustrated that corticosteroids are effective in treating rotator cuff tendonitis for up to a nine-month period and suggested that injections are more effective than NSAIDs. ${ }^{68}$ Injections have also been shown to be successful in the treatment of RTC impingement. ${ }^{69} \mathrm{~A}$ paper by Alvarez et al. found no significant difference between injections of corticosteroids plus local anesthetic versus local anesthetic alone; ${ }^{70}$ however, most practitioners prefer a steroid-containing injection.
The results of traditional physical therapy have been consistently good for treating pain relief and improving function, but less certain for maintaining strength. A study by Bang and Deyle demonstrated improvement in pain from impingement with physical therapy alone. ${ }^{71} \mathrm{~A}$ recent systematic review demonstrated that exercise has statistically and clinically significant effects on improving pain and function but not ROM and strength. ${ }^{72}$ It also revealed that supervised exercise was not significantly better than home exercise. ${ }^{72}$ Adjuvant therapy such as US, extracorporeal shock wave therapy, laser therapy, and iontophoresis have not shown any significant benefit in the treatment of RTC tears, although shock wave therapy is thought to be of benefit in calcific tendonitis. ${ }^{73-75}$

A comparison of non-operative modalities yields mixed results. Some studies have shown that corticosteroid injections are equivalent to physical therapy, while others have demonstrated better results with an injection. ${ }^{76-78} \mathrm{~A}$ Cochrane review in 2003 came to the conclusion that injections for RTC had a small benefit over placebo but no benefit over NSAIDs. ${ }^{79} \mathrm{~A}$ study of injection plus NSAIDs revealed improved outcomes as compared to non-treatment in RTC.$^{80}$ Other data show that both injection and injection plus NSAIDs provide no significant benefit when compared to each other, yet both groups have significantly improved results over placebo. ${ }^{81,82}$

\section{Operative management}

Indications for operative management of RTC disease are based largely on response to non-operative modalities and patient goals. Persistent severe or moderate pain at rest and/or with function after an initial trial of conservative treatment (3-6 months) may be best served with surgical intervention. Other indications include acute weakness in younger patients, because a study demonstrated that later repair may be more difficult in full thickness tears. ${ }^{83}$ Other authors advocate always repairing a full thickness RTC tear, regardless of the age or size of the tear..$^{84}$ Because of the advent of arthroscopic surgery and less invasive means of treating both RTC disease and associated pathologies, surgery is now recommended more frequently. In the literature, however, indications for surgical intervention are rarely reported, leaving no clear consensus for when to operate..$^{85}$

In addition to relieving pain, the goal of reconstructive surgery should be to restore normal glenohumeral kinematics and shoulder strength. The aim of surgery is to restore the anatomy by re-attaching the tendon to its footprint on the proximal humerus. ${ }^{12}$ In addition to covering the defect produced by a RTC tear, one hopes to recreate the normal moments (force couples) about the shoulder that allow concentric rotation of the humeral head about the glenoid in all planes. ${ }^{86}$ Multiple studies have demonstrated the efficacy of non-operative modalities to reduce pain but failure to restore motion and strength. ${ }^{71,72}$ This is intuitively obvious as non-surgical methods are unable to re-establish normal tendon-to-bone relationships and do not result in healing.

RTC impingement and partial thickness tearing of less than half the tendon may be treated operatively with debridement of the RTC, subacromial decompression (SAD), and acromioplasty. This is most commonly accomplished through arthroscopic techniques (Figure 11). 


\section{Surgical technique}

Treatment of impingement syndrome and RTC tears has undergone drastic changes over the past decade starting with formal open and mini-open repairs to double-row (DR), anatomic arthroscopic fixation. Even today, mini-open (arthroscopically-assisted) RTC repair, with success rates greater than $80-90 \%$, remains a benchmark to which all new techniques are compared ${ }^{87-92}$ Focus shifted to allarthroscopic repair when numerous surgeons were able to demonstrate superior results and faster return to function with arthroscopic versus open subacromial decompression for impingement syndrome. ${ }^{92-95}$ Results of allarthroscopic RTC repair have been shown to be equivalent to those of mini-open repairs with the added benefits of superior range of motion $^{96-101}$ and less risk of injury to the deltoid.

Early arthroscopic techniques utilized a single row (SR) of suture anchor fixation, which did not restore the RTC footprint anatomically. Despite satisfactory results with arthroscopic SR repairs, multiple studies have shed light on the failure of the repaired RTC to heal, with some series having failure rates as high as 94\%. ${ }^{102-108}$ These outcomes, to a certain extent, mirrored results obtained with non-operative treatment. ${ }^{71,72}$ Specifically, failure to anatomically restore the tendon to the bone resulted in a lack of tendon healing. Despite early clinical improvement, even in those that did not heal, over time this lack of healing has been associated with deteriorating functional results and has been correlated with inferior strength. . $10,109-111^{-1}$

Emphasis was then placed on restoration of the RTC footprint using DR fixation methods (two rows of anchors to fix the tendon onto the tuberosity). Multiple cadaveric studies have shown superior biomechanical properties and improved anatomic restoration with DR techniques compared to SR fixation. ${ }^{112-116}$ Furthermore, some recent DR clinical outcome studies have shown decreased re-tear rates and improved strength and functional results in those patients that have demonstrated tendon healing. ${ }^{109-111}$ However, other comparative clinical studies have shown no differences in clinical outcome between SR and DR repair techniques except in massive tears, which favored DR. ${ }^{117-121}$ The question of the best clinical method of repair presently remains unanswered as it is unclear why the increased biomechanical properties of DR repair may not lead to improved clinical outcomes.

Arthroscopic RTC repair can be performed either in the beach chair or lateral decubitus positions. Standard posterior, posterolateral, anterolateral, and anterior portals are established. Routine diagnostic arthroscopy is performed and any intra-articular glenohumeral pathology is addressed. ${ }^{87}$ Specifically, the biceps should be evaluated, as this is a common cause of concurrent pain in the patient
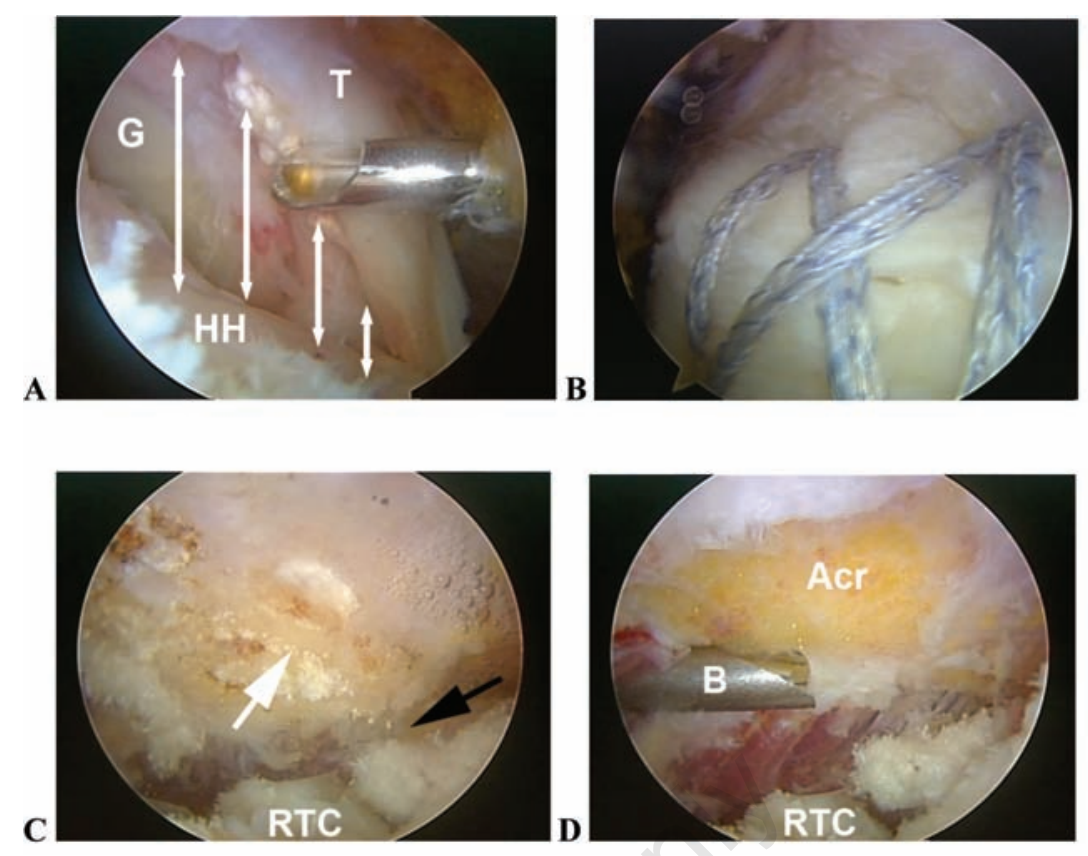

Figure 11. Intra-operative arthroscopic images: A, full-thickness RTC tear with exposed glenoid (G), arrows marking the gap between retracted tendon (T) and humeral head (HH); B, RTC tear after arthroscopic repair in double-row technique using suture anchors; $\mathrm{C}$, subacromial bone spurring (white arrow) narrowing the subacromial space (black arrow) and leading to fraying of the rotator cuff (RTC); D, arthroscopic acromioplasty with the acromion (Acr) contoured to a flat margin with an arthroscopic burr (B) entering laterally.

with rotator cuff pathology. If appropriate, biceps tenodesis is performed in the younger, active patient and simple tenotomy performed in the older, low-demand patient.

Subacromial bursectomy is performed routinely. This addresses bursitis as a possible pain generator while at the same time improving visualization. ${ }^{87}$ Acromioplasty is performed with release of the coracoacromial ligament in all but massive, irreparable tears. This is especially important in patients with a curved or hooked acromial morphology where an extrinsic impingement mechanism likely contributed to the RTC tear. ${ }^{122}$

After adequate debridement and mobilization of the torn RTC, fixation is achieved to the tuberosity of the humerus. Either SR or DR repair techniques may be utilized. ${ }^{123}$ Typically, specifically designed suture anchors are used in arthroscopic repair, although there are methods that allow trans-osseous sutures to be placed arthroscopically. Regardless of the technique utilized, it is important to achieve anatomic restoration of the tendon footprint with rigid fixation. This will ensure an optimal environment for healing and allow initiation of early ROM without fear of compromising the repair. ${ }^{124}$

For patients with massive, irreparable RTC tears, isolated debridement, subacromial decompression, and biceps tenotomy may provide adequate pain relief. ${ }^{125} \mathrm{~A}$ partial repair may help to improve the force couples in those with massive tears. When the tear is irreparable and the individual requires greater strength or function, tendon transfer and reverse shoulder arthroplasty remain options.

\section{Results of operative management}

Success rates have been reported to be 75$86 \%$ for relief of impingement symptoms. ${ }^{126,127}$ Park et al. demonstrated good results with debridement and acromioplasty alone in partial tears of $<50 \%$. ${ }^{128}$ There have been three randomized surgical trials comparing $\mathrm{SAD}$ to physical therapy. Two found SAD superior to therapy alone, ${ }^{129,130}$ while a third found no significant difference in the modalities. ${ }^{131}$ Repair of partial thickness tears is undertaken if the tear extends to involve $>50 \%$ of the thickness of the tendon. This may be accomplished through an arthroscopic or mini-open approach. ${ }^{132}$ Weber reported that debridement alone is not sufficient for RTC tears involving $>50 \%$ of the tendon. Overall success rates have been reported in the literature to be $50-89 \%$ for operative repair. ${ }^{133-135}$

The management of full thickness RTC tears depends on the size and characteristics of the tear. The vast majority are amenable to arthroscopic repair (Figure 11), although in certain cases an open approach may be needed. A 78$80 \%$ success rate with $95-98.6 \%$ patient satisfaction has been reported in the literature for arthroscopic repair with $95.5 \%$ of patients claiming they would have the repair again. ${ }^{21,136}$ 
Recently, in a study comparing a SR fixation technique with a DR technique, Park et al. showed that both groups had significant improvement regarding American Society of Shoulder and Elbow Surgeons (ASES) scores (SR: 43 preoperative to 92 postoperative and DR: 41 preoperative to 93 postoperative) and Constant shoulder scores (SR: 42 preoperative to 77 postoperative and DR: 44 preoperative to 80 postoperative). Overall, SR and DR showed no significant difference in outcomes. However, when splitting the groups into smalland medium-size tears versus large- and massive-size tears, the DR fixation of large- and massive-size tears had superior outcomes regarding the ASES and Constant scores over the SR group (DR ASES 93 and Constant 80 vs. SR ASES 90 and Constant 72). ${ }^{121}$

For massive tears (defined as $>5 \mathrm{~cm}$ ), surgery may involve a wide spectrum of procedures from arthroscopy and debridement to repair to complicated reconstructions. Good results ( $>80 \%$ patient satisfaction) have been reported from simple debridement and SAD. ${ }^{137,138}$ Some tears may be deemed irreparable secondary to tendon degeneration, retraction, and fatty infiltration of the muscle. In these cases, treatment may simply be debridement or a reconstruction of the RTC may be undertaken using the subscapularis, teres major, latissimus dorsi, or pectoralis muscle. They are all relatively new techniques, but limited early data reveal satisfactory outcomes. ${ }^{139,140}$ In addition, the use of allografts for tendon reconstruction has been reported, although in some series the results were not favorable. ${ }^{141}$

\section{Surgical complications and postoperative course}

Complications after RTC surgery include infection $(<1 \%)$, failure of repair $(6 \%)$, neurovascular damage (1\%), and stiffness (4\%), with similar rates in open and arthroscopic surgery. ${ }^{100,142}$ Postoperative management depends on the procedures performed, the quality of the tissues, and the quality of the repair. Most RTC surgeries are performed as a same day procedure. Patients treated with debridement and SAD and those with small RTC repairs are allowed early motion with physical therapy for ROM and strengthening. RTC repair for medium-size tears are immobilized for two weeks, then physical therapy is initiated. Larger tears, or those with poor quality tissues, may be protected for six weeks with limited ROM followed by physical therapy for ROM and strengthening at 10 weeks. Complete recovery typically takes 4-6 months, although it varies depending on age, size of tear, tissue quality, comorbidities, and patient motivation. ${ }^{143}$

\section{Summary}

Pathology of the RTC tendons is a frequent cause of shoulder pain and disability and may be seen in both the young and elderly. Patients typically present with a specific set of symptoms and have diagnostic findings on physical examination. History and physical examination findings may be confirmed with imaging, most commonly including radiographs followed by MRI or US. RTC disease includes a spectrum of disorders from impingement and tendinopathy to full thickness tears of the RTC tendons. The majority of patients with impingement and partial thickness tears can be managed non-operatively including NSAIDs, steroid injections, and physical therapy, with good outcomes. However, some partial thickness tears, acute full thickness tears in the young, and full thickness tears in older patients refractory to non-operative management may require operative intervention. Surgery may be accomplished with good results through an open or arthroscopic approach. Most tears can now be managed with the less invasive arthroscopic approach with favorable outcomes.

\section{References}

1. Lin JC, Weintraub N, Aragaki DR. Nonsurgical treatment for rotator cuff injury in the elderly. J Am Med Dir Assoc 2008;9:626-32.

2. Braun S, Kokmeyer D, Millett PJ. Shoulder injuries in the throwing athlete. J Bone Joint Surg Am 2009;91:966-78.

3. Fukuda H. Partial-thickness rotator cuff tears: a modern view on Codman's classic. J Shoulder Elbow Surg 2000;9:163-8.

4. Fukuda $H$. The management of partialthickness tears of the rotator cuff. J Bone Joint Surg Br 2003;85:3-11.

5. Praemer AFS, Rice D. Musculoskeletal conditions in the United States. 2nd ed. Rosemont, IL: American Academy of Orthopaedic Surgeons, 1999.

6. Codman EA. The Shoulder: Rupture of the Supraspinatus Tendon and Other Lesions in or About the Subacromial Bursa. Boston MTT, 1934.

7. Yamaguchi K, Ditsios K, Middleton WD, et al. The demographic and morphological features of rotator cuff disease. A comparison of asymptomatic and symptomatic shoulders. J Bone Joint Surg Am 2006;88: 1699-704.

8. Sher JS, Uribe JW, Posada A, et al. Abnormal findings on magnetic resonance images of asymptomatic shoulders. J Bone Joint Surg Am 1995;77:10-5.
9. Milgrom C, Schaffler M, Gilbert S, et al. Rotator-cuff changes in asymptomatic adults. The effect of age, hand dominance and gender. J Bone Joint Surg Br 1995; 77:296-8.

10. Yamamoto A, Takagishi K, Osawa T, et al. Prevalence and risk factors of a rotator cuff tear in the general population. J Shoulder Elbow Surg 2010;19:116-20.

11. DeFranco MJ, Cole BJ. Current perspectives on rotator cuff anatomy. Arthroscopy 2009;25:305-20.

12. Dugas JR, Campbell DA, Warren RF, et al. Anatomy and dimensions of rotator cuff insertions. J Shoulder Elbow Surg 2002;11: 498-503.

13. Neer CS 2nd. Anterior acromioplasty for the chronic impingement syndrome in the shoulder: a preliminary report. J Bone Joint Surg Am 1972;54:41-50.

14. Walch G, Liotard JP, Boileau P, et al. [Postero-superior glenoid impingement. Another impingement of the shoulder]. J Radiol 1993;74:47-50.

15. Ogata S, Uhthoff HK. Acromial enthesopathy and rotator cuff tear. A radiologic and histologic postmortem investigation of the coracoacromial arch. Clin Orthop Relat Res 1990;254:39-48.

16. Neer CS 2nd. Impingement lesions. Clin Orthop Relat Res 1983;173:70-7.

17. Gotoh M, Hamada K, Yamakawa H, et al. Interleukin-1-induced subacromial synovitis and shoulder pain in rotator cuff diseases. Rheumatology 2001;40:995-1001.

18. Gotoh M, Hamada K, Yamakawa H, Y et al. Interleukin-1-induced glenohumeral synovitis and shoulder pain in rotator cuff diseases. J Orthop Res 2002;20:1365-71.

19. Ellman H. Diagnosis and treatment of incomplete rotator cuff tears. Clin Orthop Relat Res 1990;254:64-74.

20. Wolff AB, Sethi P, Sutton KM, et al. Partialthickness rotator cuff tears. J Am Acad Orthop Surg 2006;14:715-25.

21. Cofield RH, Parvizi J, Hoffmeyer PJ, et al. Surgical repair of chronic rotator cuff tears. A prospective long-term study. J Bone Joint Surg Am 2001;83-A:71-7.

22. Goutallier D, Postel JM, Gleyze P, et al. Influence of cuff muscle fatty degeneration on anatomic and functional outcomes after simple suture of full-thickness tears. J Shoulder Elbow Surg 2003;12:550-4.

23. Goutallier D, Postel JM, Bernageau J, et al. Fatty muscle degeneration in cuff ruptures. Pre- and postoperative evaluation by CT scan. Clin Orthop Relat Res 1994;304: 78-83.

24. Fuchs B, Weishaupt D, Zanetti M, et al. Fatty degeneration of the muscles of the rotator cuff: assessment by computed tomography versus magnetic resonance imaging. J Shoulder Elbow Surg 1999;8: 
599-605.

25. Green A. Chronic massive rotator cuff tears: evaluation and management. J Am Acad Orthop Surg 2003;11:321-31.

26. Bey MJ, Ramsey ML, Soslowsky LJ. Intratendinous strain fields of the supraspinatus tendon: effect of a surgically created articular-surface rotator cuff tear. J Shoulder Elbow Surg 2002;11:562-9.

27. Gotoh M, Hamada K, Yamakawa H, et al. Increased substance $\mathrm{P}$ in subacromial bursa and shoulder pain in rotator cuff diseases. J Orthop Res 1998;16:618-21.

28. Walch G, Boulahia A, Calderone S, et al. The 'dropping' and 'hornblower's' signs in evaluation of rotator-cuff tears. J Bone Joint Surg Br 1998;80:624-8.

29. Hertel R, Ballmer FT, Lombert SM, et al. Lag signs in the diagnosis of rotator cuff rupture. J Shoulder Elbow Surg 1996;5: 307-13.

30. Hawkins RJ, Kennedy JC. Impingement syndrome in athletes. Am J Sports Med 1980;8:151-8.

31. Beaudreuil J, Nizard R, Thomas T, et al. Contribution of clinical tests to the diagnosis of rotator cuff disease: a systematic literature review. Joint Bone Spine 2009;76: 15-9.

32. Silva L, Andreu JL, Munoz P, et al. Accuracy of physical examination in subacromial impingement syndrome. Rheumatology 2008;47:679-83.

33. Gomoll AH, Katz JN, Warner JJ, et al. Rotator cuff disorders: recognition and management among patients with shoulder pain. Arthritis Rheum 2004;50:375161.

34. Weiner DS, Macnab I. Superior migration of the humeral head. A radiological aid in the diagnosis of tears of the rotator cuff. J Bone Joint Surg Br 1970;52:524-7.

35. Pearsall AW, Bonsell S, Heitman RJ, et al. Radiographic findings associated with symptomatic rotator cuff tears. J Shoulder Elbow Surg 2003;12:122-7.

36. Itoi E, Tabata S. Incomplete rotator cuff tears. Results of operative treatment. Clin Orthop Relat Res 1992;284:128-35.

37. Gartsman GM, Milne JC. Articular surface partial-thickness rotator cuff tears. J Shoulder Elbow Surg 1995;4:409-15.

38. Fukuda H, Mikasa M, Yamanaka K. Incomplete thickness rotator cuff tears diagnosed by subacromial bursography. Clin Orthop Relat Res 1987;223:51-8.

39. Charousset C, Bellaiche L, Duranthon LD, et al. Accuracy of CT arthrography in the assessment of tears of the rotator cuff. J Bone Joint Surg Br 2005;87:824-8.

40. Hedtmann A, Fett H. [Ultrasound diagnosis of the rotator cuff]. Orthopade 2002; 31:236-46.

41. Ziegler DW. The use of in-office, orthopaedist-performed ultrasound of the shoulder to evaluate and manage rotator cuff disorders. J Shoulder Elbow Surg 2004;13:291-7.

42. Gusmer PB, Potter HG, Schatz JA, et al. Labral injuries: accuracy of detection with unenhanced MR imaging of the shoulder. Radiology 1996;200:519-24.

43. Connell DA, Potter HG, Wickiewicz TL, et al. Noncontrast magnetic resonance imaging of superior labral lesions. 102 cases confirmed at arthroscopic surgery. Am J Sports Med 1999;27:208-13.

44. de Jesus J0, Parker L, Frangos AJ, et al. Accuracy of MRI, MR arthrography, and ultrasound in the diagnosis of rotator cuff tears: a meta-analysis. Am J Roentgenol 2009;192:1701-7.

45. Teefey SA, Rubin DA, Middleton WD, et al. Detection and quantification of rotator cuff tears. Comparison of ultrasonographic, magnetic resonance imaging, and arthroscopic findings in seventy-one consecutive cases. J Bone Joint Surg Am 2004; 86-A:708-16.

46. Fotiadou AN, Vlychou M, Papadopoulos P, et al. Ultrasonography of symptomatic rotator cuff tears compared with MR imaging and surgery. Eur J Radiol 2008;68:1749.

47. Chansky HA, Iannotti JP. The vascularity of the rotator cuff. Clin Sports Med 1991;10: 807-22.

48. Stetson WB, Phillips T, Deutsch A. The use of magnetic resonance arthrography to detect partial-thickness rotator cuff tears. J Bone Joint Surg Am 2005;87:S81-8.

49. Waldt S, Bruegel M, Mueller D, et al. Rotator cuff tears: assessment with MR arthrography in 275 patients with arthroscopic correlation. Eur Radiol 2007;17:4918.

50. Galatz LM, Silva MJ, Rothermich SY, et al. Nicotine delays tendon-to-bone healing in a rat shoulder model. J Bone Joint Surg Am 2006;88:2027-34.

51. Kearney PM, Baigent C, Godwin J, et al. Do selective cyclo-oxygenase-2 inhibitors and traditional non-steroidal anti-inflammatory drugs increase the risk of atherothrombosis? Meta-analysis of randomised trials. Br Med J 2006;332:1302-8.

52. Anderson JL, Adams CD, Antman EM, et al. ACC/AHA 2007 guidelines for the management of patients with unstable angina/non ST-elevation myocardial infarction: a report of the American College of Cardiology/American Heart Association Task Force on Practice Guidelines (Writing Committee to Revise the 2002 Guidelines for the Management of Patients With Unstable Angina/Non STElevation Myocardial Infarction): developed in collaboration with the American
College of Emergency Physicians, the Society for Cardiovascular Angiography and Interventions, and the Society of Thoracic Surgeons: endorsed by the American Association of Cardiovascular and Pulmonary Rehabilitation and the Society for Academic Emergency Medicine. Circulation 2007;116:e148-304.

53. Speed CA. Fortnightly review: Corticosteroid injections in tendon lesions. $\mathrm{Br}$ Med J 2001;323:382-6.

54. Bokor DJ, Hawkins RJ, Huckell GH, et al. Results of nonoperative management of full-thickness tears of the rotator cuff. Clin Orthop Relat Res 1993;294:103-10.

55. Wirth MA, Basamania C, Rockwood CA Jr. Nonoperative management of full-thickness tears of the rotator cuff. Orthop Clin North Am 1997;28:59-67.

56. Hawkins RH, Dunlop R. Nonoperative treatment of rotator cuff tears. Clin Orthop Relat Res 1995;321:178-88.

57. van der Windt DA, van der Heijden GJ, Scholten RJ, et al. The efficacy of nonsteroidal anti-inflammatory drugs (NSAIDS) for shoulder complaints. A systematic review. J Clin Epidemiol 1995;48: 691-704.

58. Heller B, Tarricone R. Oxaprozin versus diclofenac in NSAID-refractory periarthritis pain of the shoulder. Curr Med Res Opin 2004;20:1279-90.

59. Friis J, Jarner D, Toft B, et al. Comparison of two ibuprofen formulations in the treatment of shoulder tendonitis. Clin Rheumatol 1992;11:105-8.

60. Duke 0, Zecler E, Grahame R. Anti-inflammatory drugs in periarthritis of the shoulder: a double-blind, between-patient study of naproxen versus indomethacin. Rheumatol Rehabil 1981;20:54-9.

61. Smith MD, Thomas D, McCredie M, et al. Piroxicam versus naproxen in the treatment of painful shoulder. Pharmatherapeutica 1986;4:585-9.

62. Bertin P, Behier JM, Noel E, et al. Celecoxib is as efficacious as naproxen in the management of acute shoulder pain. $\mathbf{J}$ Int Med Res 2003;31:102-12.

63. McGettigan P, Henry D. Cardiovascular risk and inhibition of cyclooxygenase: a systematic review of the observational studies of selective and nonselective inhibitors of cyclooxygenase 2. J Am Med Assoc 2006;296:1633-44.

64. Yamakado K. The targeting accuracy of subacromial injection to the shoulder: an arthrographic evaluation. Arthroscopy 2002;18:887-91.

65. Eustace JA, Brophy DP, Gibney RP, et al. Comparison of the accuracy of steroid placement with clinical outcome in patients with shoulder symptoms. Ann Rheum Dis 1997;56:59-63. 
66. Henkus HE, Cobben LP, Coerkamp EG, et al. The accuracy of subacromial injections: a prospective randomized magnetic resonance imaging study. Arthroscopy 2006;2 2:277-82.

67. Chen MJ, Lew HL, Hsu TC, et al. Ultrasound-guided shoulder injections in the treatment of subacromial bursitis. Am J Phys Med Rehabil 2006;85:31-5.

68. Arroll B, Goodyear-Smith F. Corticosteroid injections for painful shoulder: a metaanalysis. Br J Gen Pract 2005;55:224-8.

69. Blair B, Rokito AS, Cuomo F, et al. Efficacy of injections of corticosteroids for subacromial impingement syndrome. J Bone Joint Surg Am 1996;78:1685-9.

70. Alvarez CM, Litchfield R, Jackowski D, et al. A prospective, double-blind, randomized clinical trial comparing subacromial injection of betamethasone and xylocaine to xylocaine alone in chronic rotator cuff tendinosis. Am J Sports Med 2005;33:25562.

71. Bang MD, Deyle GD. Comparison of supervised exercise with and without manual physical therapy for patients with shoulder impingement syndrome. J Orthop Sports Phys Ther 2000;30:126-37.

72. Kuhn JE. Exercise in the treatment of rotator cuff impingement: a systematic review and a synthesized evidence-based rehabilitation protocol. J Shoulder Elbow Surg 2009;18:138-60.

73. Vecchio P, Cave M, King V, et al. A doubleblind study of the effectiveness of low level laser treatment of rotator cuff tendinitis. Br J Rheumatol1993;32:740-2.

74. Schmitt J, Haake M, Tosch A, et al. Lowenergy extracorporeal shock-wave treatment (ESWT) for tendinitis of the supraspinatus. A prospective, randomised study. J Bone Joint Surg Br 2001;83:873-6.

75. Pan PJ, Chou CL, Chiou HJ, et al. Extracorporeal shock wave therapy for chronic calcific tendinitis of the shoulders: a functional and sonographic study. Arch Phys Med Rehabil 2003;84:988-93.

76. Ginn KA, Cohen ML. Exercise therapy for shoulder pain aimed at restoring neuromuscular control: a randomized comparative clinical trial. J Rehabil Med 2005;37: 115-22.

77. Hay EM, Thomas E, Paterson SM, et al. A pragmatic randomised controlled trial of local corticosteroid injection and physiotherapy for the treatment of new episodes of unilateral shoulder pain in primary care. Ann Rheum Dis 2003;62:394-9.

78. van der Windt DA, Koes BW, Deville W, et al. Effectiveness of corticosteroid injections versus physiotherapy for treatment of painful stiff shoulder in primary care: randomised trial. Br Med J 1998;317:12926.
79. Green SBR, Hetrick S. Physiotherapy interventions for shoulder pain. Cochrane Database Syst Rev 2003;2:CD004258.

80. Petri M, Dobrow R, Neiman R, et al. Randomized, double-blind, placebo-controlled study of the treatment of the painful shoulder. Arthritis Rheum 1987;30: 1040-5.

81. Adebajo A0, Nash P, Hazleman BL. A prospective double blind dummy placebo controlled study comparing triamcinolone hexacetonide injection with oral diclofenac $50 \mathrm{mg}$ TDS in patients with rotator cuff tendinitis. J Rheumatol 1990; 17:120710.

82. White RH, Paull DM, Fleming KW. Rotator cuff tendinitis: comparison of subacromial injection of a long acting corticosteroid versus oral indomethacin therapy. $\mathrm{J}$ Rheumatol 1986;13:608-13.

83. Bassett RW, Cofield RH. Acute tears of the rotator cuff. The timing of surgical repair. Clin Orthop Relat Res 1983;175:18-24.

84. Lahteenmaki HE, Hiltunen A, Virolainen P, et al. Repair of full-thickness rotator cuff tears is recommended regardless of tear size and age: a retrospective study of 218 patients. J Shoulder Elbow Surg 2007;16: 586-90.

85. Marx RG, Koulouvaris P, Chu SK, et al. Indications for surgery in clinical outcome studies of rotator cuff repair. Clin Orthop Relat Res 2009;467:450-6.

86. Burkhart SS, Lo IK. Arthroscopic rotator cuff repair. J Am Acad Orthop Surg 2006;14:333-46.

87. Gartsman GM. Arthroscopic management of rotator cuff disease. J Am Acad Orthop Surg 1998;6:259-66.

88. Burkhart SS, Nottage WM, Ogilvie-Harris DJ, et al. Partial repair of irreparable rotator cuff tears. Arthroscopy 1994;10:363-70.

89. Levy HJ, Uribe JW, Delaney LG. Arthroscopic assisted rotator cuff repair: preliminary results. Arthroscopy 1990;6: $55-60$.

90. Liu SH, Baker CL. Arthroscopically assisted rotator cuff repair: correlation of functional results with integrity of the cuff. Arthroscopy 1994;10:54-60.

91. Paulos LE, Kody MH. Arthroscopically enhanced 'miniapproach' to rotator cuff repair. Am J Sports Med 1994;22:19-25.

92. Blevins FT, Warren RF, Cavo C, et al. Arthroscopic assisted rotator cuff repair: results using a mini-open deltoid splitting approach. Arthroscopy 1996;12:50-9.

93. Esch JC, Ozerkis LR, Helgager JA, et al. Arthroscopic subacromial decompression: results according to the degree of rotator cuff tear. Arthroscopy 1988;4:241-9.

94. Norlin R. Arthroscopic subacromial decompression versus open acromioplasty. Arthroscopy 1989;5:321-3.
95. Van Holsbeeck E, DeRycke J, Declercq G, et al. Subacromial impingement: open versus arthroscopic decompression. Arthroscopy 1992;8:173-8.

96. Gartsman GM, Khan M, Hammerman SM. Arthroscopic repair of full-thickness tears of the rotator cuff. J Bone Joint Surg Am 1998;80:832-40.

97. Severud EL, Ruotolo C, Abbott DD, et al. All-arthroscopic versus mini-open rotator cuff repair: A long-term retrospective outcome comparison. Arthroscopy 2003;19: 234-8.

98. Warner JJ, Tetreault P, Lehtinen J, et al. Arthroscopic versus mini-open rotator cuff repair: a cohort comparison study. Arthroscopy 2005;21:328-32.

99. Buess E, Steuber KU, Waibl B. Open versus arthroscopic rotator cuff repair: a comparative view of 96 cases. Arthroscopy 2005;21:597-604.

100.Morse K, Davis AD, Afra R, et al. Arthroscopic versus mini-open rotator cuff repair: a comprehensive review and metaanalysis. Am J Sports Med 2008;36:1824-8.

101.Boileau P, Brassart N, Watkinson DJ, et al. Arthroscopic repair of full-thickness tears of the supraspinatus: does the tendon really heal? J Bone Joint Surg Am 2005;87: 1229-40.

102.Calvert PT, Packer NP, Stoker DJ, et al. Arthrography of the shoulder after operative repair of the torn rotator cuff. J Bone Joint Surg Br 1986;68:147-50.

103.Harryman DT 2nd, Mack LA, Wang KY, et al. Repairs of the rotator cuff. Correlation of functional results with integrity of the cuff. J Bone Joint Surg Am 1991;73:982-9.

104.Knudsen HB, Gelineck J, Sojbjerg J0, et al. Functional and magnetic resonance imaging evaluation after single-tendon rotator cuff reconstruction. J Shoulder Elbow Surg 1999;8:242-6.

105.Cole BJ, McCarty LP 3rd, Kang RW, et al. Arthroscopic rotator cuff repair: prospective functional outcome and repair integrity at minimum 2-year follow-up. J Shoulder Elbow Surg 2007;16:579-85.

106.Galatz LM, Ball CM, Teefey SA, et al. The outcome and repair integrity of completely arthroscopically repaired large and massive rotator cuff tears. J Bone Joint Surg Am 2004;86-A:219-24.

107.Bishop J, Klepps S, Lo IK, et al. Cuff integrity after arthroscopic versus open rotator cuff repair: a prospective study. $\mathrm{J}$ Shoulder Elbow Surg 2006;15:290-9.

108.Anderson K, Boothby M, Aschenbrener D, et al. Outcome and structural integrity after arthroscopic rotator cuff repair using 2 rows of fixation: minimum 2-year followup. Am J Sports Med 2006;34:1899-905.

109.Huijsmans PE, Berghs BM, van Rooyen $\mathrm{KS}$, et al. Arthroscopic rotator cuff repair 
with double-row fixation. J Bone Joint Surg Am 2007;89:1248-57.

110.Lafosse L, Brozska R, Toussaint B, et al. The outcome and structural integrity of arthroscopic rotator cuff repair with use of the double-row suture anchor technique. J Bone Joint Surg Am 2007;89:1533-41.

111.Sugaya H, Maeda K, Matsuki K, et al. Repair integrity and functional outcome after arthroscopic double-row rotator cuff repair. A prospective outcome study. J Bone Joint Surg Am 2007;89:953-60.

112.Kim DH, Elattrache NS, Tibone JE, et al. Biomechanical comparison of a single-row versus double-row suture anchor technique for rotator cuff repair. Am J Sports Med 2006;34:407-14.

113.Meier SW, Meier JD. Rotator cuff repair: the effect of double-row fixation on threedimensional repair site. J Shoulder Elbow Surg 2006;15:691-6.

114.Park MC, ElAttrache NS, Tibone JE, et al. Part I: Footprint contact characteristics for a transosseous-equivalent rotator cuff repair technique compared with a doublerow repair technique. J Shoulder Elbow Surg 2007;16:461-8.

115.Ma CB, Comerford L, Wilson J, et al. Biomechanical evaluation of arthroscopic rotator cuff repairs: double-row compared with single-row fixation. J Bone Joint Surg Am 2006;88:403-10.

116.Park MC, Tibone JE, ElAttrache NS, et al. Part II: Biomechanical assessment for a footprint-restoring transosseous-equivalent rotator cuff repair technique compared with a double-row repair technique. J Shoulder Elbow Surg 2007;16:469-76.

117.Sugaya H, Maeda K, Matsuki K, et al. Functional and structural outcome after arthroscopic full-thickness rotator cuff repair: single-row versus dual-row fixation. Arthroscopy 2005;21:1307-16.

118.Burks RT, Crim J, Brown N, et al. A prospective randomized clinical trial comparing arthroscopic single- and doublerow rotator cuff repair: magnetic resonance imaging and early clinical evaluation. Am J Sports Med 2009;37:674-82.

119.Grasso A, Milano G, Salvatore M, et al. Single-row versus double-row arthroscopic rotator cuff repair: a prospective randomized clinical study. Arthroscopy 2009;25:412.

120.Franceschi F, Ruzzini L, Longo UG, et al.
Equivalent clinical results of arthroscopic single-row and double-row suture anchor repair for rotator cuff tears: a randomized controlled trial. Am J Sports Med 2007; 35:1254-60.

121.Park JY, Lhee SH, Choi JH, et al. Comparison of the clinical outcomes of single- and double-row repairs in rotator cuff tears. Am J Sports Med 2008;36:13106.

122.Nirschl RP. Rotator cuff surgery. Instr Course Lect 1989;38:447-62.

123.Wall LB, Keener JD, Brophy RH. Clinical outcomes of double-row versus single-row rotator cuff repairs. Arthroscopy 2009; 25:1312-8.

124.Park MC, Elattrache NS. Treating fullthickness cuff tears in the athlete: advances in arthroscopic techniques. Clin Sports Med 2008;27:719-29.

125.Liem D, Lichtenberg S, Magosch P, et al. Arthroscopic rotator cuff repair in overhead-throwing athletes. Am J Sports Med 2008;36:1317-22.

126. Hawkins RJ, Plancher KD, Saddemi SR, et al. Arthroscopic subacromial decompression. J Shoulder Elbow Surg 2001;10:22530.

127.Patel VR, Singh D, Calvert PT, et al. Arthroscopic subacromial decompression: results and factors affecting outcome. J Shoulder Elbow Surg 1999;8:231-7.

128.Park JY, Yoo MJ, Kim MH. Comparison of surgical outcome between bursal and articular partial thickness rotator cuff tears. Orthopedics 2003;26:387-90; discussion 90 .

129.Rahme H, Solem-Bertoft E, Westerberg CE, et al. The subacromial impingement syndrome. A study of results of treatment with special emphasis on predictive factors and pain-generating mechanisms. Scand J Rehabil Med 1998;30:253-62.

130.Brox JI, Gjengedal E, Uppheim G, et al. Arthroscopic surgery versus supervised exercises in patients with rotator cuff disease (stage II impingement syndrome): a prospective, randomized, controlled study in 125 patients with a $21 / 2$-year follow-up. J Shoulder Elbow Surg 1999;8:102-11.

131.Haahr JP, Ostergaard S, Dalsgaard J, et al. Exercises versus arthroscopic decompression in patients with subacromial impingement: a randomised, controlled study in 90 cases with a one year follow up.
Ann Rheum Dis 2005;64:760-4.

132.Cordasco FA, Bigliani LU. The rotator cuff. Large and massive tears. Technique of open repair. Orthop Clin North Am 1997; 28:179-93.

133.0gilvie-Harris DJ, Wiley AM. Arthroscopic surgery of the shoulder. A general appraisal. J Bone Joint Surg Br 1986;68:201-7.

134.Budoff JE, Nirschl RP, Guidi EJ. Debridement of partial-thickness tears of the rotator cuff without acromioplasty. Long-term follow-up and review of the literature. J Bone Joint Surg Am 1998;80: 733-48.

135.Snyder SJ, Pachelli AF, Del Pizzo W, et al. Partial thickness rotator cuff tears: results of arthroscopic treatment. Arthroscopy 1991;7:1-7.

136.Bennett WF. Arthroscopic repair of massive rotator cuff tears: a prospective cohort with 2- to 4-year follow-up. Arthroscopy 2003;19:380-90.

137.Gartsman GM. Massive, irreparable tears of the rotator cuff. Results of operative debridement and subacromial decompression. J Bone Joint Surg Am 1997;79:71521.

138. Rockwood CA Jr, Williams GR Jr, Burkhead WZ Jr. Debridement of degenerative, irreparable lesions of the rotator cuff. J Bone Joint Surg Am 1995;77:857-66.

139.Miniaci A, MacLeod M. Transfer of the latissimus dorsi muscle after failed repair of a massive tear of the rotator cuff. A two to five-year review. J Bone Joint Surg Am 1999;81:1120-7.

140.Iannotti JP, Hennigan S, Herzog R, et al. Latissimus dorsi tendon transfer for irreparable posterosuperior rotator cuff tears. Factors affecting outcome. J Bone Joint Surg Am 2006;88:342-8.

141.Bond JL, Dopirak RM, Higgins J, et al. Arthroscopic replacement of massive, irreparable rotator cuff tears using a GraftJacket allograft: technique and preliminary results. Arthroscopy 2008;24:403$9 \mathrm{e} 1$.

142.Mansat P, Cofield RH, Kersten TE, et al. Complications of rotator cuff repair. Orthop Clin North Am 1997;28:205-13.

143.Millett PJ, Wilcox RB 3rd, O'Holleran JD, et al. Rehabilitation of the rotator cuff: an evaluation-based approach. J Am Acad Orthop Surg 2006;14:599-609. 